prevented or treated if safe and effective methods are available. In Japan, most (probably all) children when they develop varicella visit their doctor because parents know that children with the disease are often uncomfortable, febrile, irritable, and unhappy and they look to doctors to prevent or reduce these problems. There is also an increasing number of children who receive a live varicella vaccine, which costs approximately 10000 yen (about $£ 65$ ) in Japan. More than 200000 children received the vaccine in 1993, which clearly indicates a strong parental need to have their children free from the disease.

Dr Conway questions whether a rise in antibody titre from $<4$ to 8 reflects seroconversion. We believe it is an obvious seroconversion and a significant (a fourfold) increase in the antibody titres, which would surely be supported by clinical virologists. We followed up children who did not show seroconversion and found that most of them had antibody activity two to three months later (unpublished data), which suggests that administration of acyclovir in the incubation period tends to postpone development of immune response to the virus. We also found that immunity to the virus persisted for at least one year in most of the children treated with acyclovir (unpublished data). It is therefore possible that the actual seroconversion rate is higher than reported. As suggested by Dr Conway the optimal dose of acyclovir that prevents the disease but induces virus immunity should be established.

It is unlikely that immunity in children treated with acyclovir tends to decline or diminish, thereby creating a risk of more severe varicella or early zoster later in life. Reduced frequency and severity of the skin rash in children treated with acyclovi suggests that the drug prevents or reduces blood borne dissemination of the virus and infection of skin with the virus. ${ }^{2-4}$ Possibly the drug suppresses replication of the virus in the lung, liver, spleen, and other organs before or during the second viraemia. ${ }^{5}$ Many of the children given acyclovir developed the virus antibodies and most of them had no signs and symptoms of varicella. All this suggests that subclinical infection is occurring. As fluorescent antibody to membrane antigen assay measures antibodies to glycoproteins or late antigens of the virus, it is reasonable to consider that a limited virus replication conferred specific memory to the virus in the immune system of children treated with acyclovir. Moreover, it is likely that the immunity will persist for a long time, as subclinical infection in a natural setting and infection with live varicella vaccine provide a long lasting immunity to the virus and protect the infected individual from the disease. ${ }^{6}$

Little is known about the mechanism by which the virus establishes latency in sensory ganglia. However, it is generally believed that the virus may arrive at the sensory ganglia not only via a nerve but also via the haematogenous route during the viraemic phase of varicella. It is unlikely that acyclovir treatmen during the incubation period predisposes the host to a higher risk of reactivation of disease (herpes zoster), as there was protection against rash and probably a reduced degree of viraemia in treated patients.

YOSHIZO ASANO SADAO SUGA TETSUSHI YOSHIKAWA Department of Paediatrics, rsity School of Medicine, Toyoake, Aichi 470-11,
TAKAO OZAKI

Department of Paediatrics, Showa Hospital, Konan, Aichi,

Japan

1 Suga S, Yoshikawa T, Ozaki T, Asano Y. Effect of oral acyclovir against primary and secondary viraemia in incubation period of varicella. Arch Dis Child 1993; 69: 639-43.

2 Asano Y, Itakura N, Hiroishi Y, et al. Viral replication and immunologic responses in children naturally infected with varicella-zoster virus and in varicella vaccine recipients. F Infect Dis 1985 152: 863-8.

3 Asano Y, Itakura N, Kajita Y, et al. Severity of viremia and clinical findings in children with varicella. F Infect Dis 1990; 161: 1095-8.

4 Asano Y, Yoshikawa T, Suga S, et al. Postexposure prophylaxis of varicella in family contact by oral acyclovir. Pediatrics 1993; 92: 219-22.

5 Asano Y, Yoshikawa T, Urisu A, Yazaki T, Mizoguchi Y, Kurata T. Varicella-zoster virus replication site in internal organs of an otherwise healthy child with varicella and sudden death. Acta Paediatr fpn $_{p n} 1993$; 35: sudden

6 Asano Y, Nagai T, Miyata T, et al. Long-term protective immunity of recipients of the OKA strain of live varicella vaccine. Pediatrics 1985 75: $667-71$.

\section{Simultaneous pulmonary infection with respiratory syncytial virus and human} cytomegalovirus

EDITOR,--Respiratory syncytial virus (RSV) is the major cause of acute lower respiratory tract illness in infants and young children. The presentation and subsequent course of RSV bronchiolitis may be atypical in the presence of a simultaneous infection with other viral agents. ${ }^{12}$ During the winter 1991-2, we studied children hospitalised for respiratory disease in a paediatric unit in Marseille. All patients were tested for viral infections and an information chart was made to determine the prevalence of multiple viral isolates and to assess the impact of dual infections on the severity of clinical disease.

Between December 1991 and February 1992, 405 children were hospitalised for respiratory disease. In all cases, nasopharyngeal wash specimens were taken on admission to the paediatric unit and simultaneously submitted to human cytomegalovirus isolation and respiratory virus fluorescent antibody staining. For human cytomegalovirus isolation, specimens were inoculated on human embryonic lung fibroblasts and a monoclonal antibody directed against the immediate early antigen (E13, Biosoft, Clonatec, France) was added 48 hours later to detect viral antigen expression. Simultaneously, indirect immunofluorescence assay was performed directly on nasopharyngeal secretions, using monoclonal specific antibodies against several viruses: RSV, influenza $A$ virus, influenza $B$ virus, parainfluenza virus type 1,2 , and 3 (Monofluo kit, Pasteur, France), and adenovirus (Biosoft, Clonatec, France).

The following information was obtained for each patient: age, sex, history and clinical symptoms, other infections, duration of hospitalisation, socioeconomic status, and ethnic group.

From the 405 children hospitalised for bronchiolitis or respiratory disease, 195 $(48 \%)$ presented viral infection: 165 were positive for RSV, 30 were positive for human cytomegalovirus, and 20 were simultaneously infected with RSV and human cytomegalovirus.
Given the frequency of RSV-human cytomegalovirus coinfection in our series $(10 \%)$, we studied these 20 children. The sex ratio was $1: 1$ and they were aged 1 month to 8 years. Fourteen of them were less than 4 months old, hence they may have had congenital or perinatal human cytomegalovirus infection. However, six were from 6 months to 8 years old. One child had oral candidosis and one was simultaneously infected with Haemophilus influenzae and rotavirus, one had a history of pneumonitis, but all were without underlying disease. Most of them were from low socioeconomic groups. Three were of Spanish extraction, seven were North Africans, and two were black children. No specific clinical situation was correlated with the coinfection: five had fever over $39^{\circ} \mathrm{C}$, four had severe bronchiolitis or pneumonitis requiring corticotherapy. But the severity of the children's illness was demonstrated by the duration of hospitalisation: the average was $6 \cdot 6$ days compared with $3 \cdot 2$ days in RSV isolated infection.

We especially noted the frequency of RSVhuman cytomegalovirus simultaneous infections in the children hospitalised for lower respiratory tract disease. But the exact role of human cytomegalovirus in bronchiolitis remains unclear ${ }^{34}$ and further clinical and biological investigations should be undertaken.

CHRISTINE M ZANDOTTI XAVIER N CATHERINE VIGNOLI JEAN-MARC GARNIER University Timone Hospital, 13385 Marseille, France

1 Subbarao E, Griffis J, Wasser JL. Detection of multiple viral agents in nasopharyngeal specimens yielding respiratory syncitial virus (RSV). An assessment of diagnostic strategy and clinical significance. Diagn Microbiol Infect Dis 1989; 12: 327--32

2 Tristram DA, Miller RW, McMillan JA, Weiner LB. Simultaneous infection with respiratory syncytial virus and other respiratory pathogens. Am f Dis Child 1988; 142: 834-6.

3 Ray CG, Holberg CJ, Minnich LL, Shehab ZM, Wright AL, Taussig LM. Acute lower respiratory illness during the first three years of life: potential roles for various etiologic agents. The Group Health Medical Associates. Pediatr Infect Dis ₹ 1993; 12: 10-4

4 Smith SD, Cho CT, Brahmacupta N, Lenahan MF. Pulmonary involvement with cytomegalovirus infections in children. Arch Dis Child 1977; 52: 441-6 Approximately $40 \%$ of those with children under 16 years felt that their children helped more than they normally would with personal care. However, from the parents' point of view it did not all seem to be bad. Approximately $40 \%$ felt that the multiple sclerosis had had little or no effect on their 